\title{
A Study of Impact of Nutrition on Targeted Height among Adolescent Girls
}

\author{
Dr. Punukollu srinivas ${ }^{1}, *$ Dr.velampalli shashikala ${ }^{2}$, DrA.Aparna ${ }^{3}$, Dr.T.pavan ${ }^{4}$ \\ ${ }^{I}$ Assistant professorof Paediatrics in NilouferHospital,Osmania Medical college, Hyderabad \\ ${ }^{2}$ Assistant Professor of Paediatrics in NilouferHospital,Osmania Medical college, Hyderabad \\ ${ }^{3}$ Professor of Paediatrics in NilouferHospital,Osmania Medical college Hyderabad \\ ${ }^{4}$ Post graduate in Paediatrics in NilouferHospital,Osmania Medical college, Hyderabad \\ Corresponding Author: "Dr. velampalli shashikala ${ }^{2}$,Flat no 203,H.no 16-11-20/6/1/6,TNR'S Raghupathi \\ Sadanam,Saleemnagar,Malakpet,Hyderabad,Telangana-500036.E Mail:docvsk@gmail.com,
}

\begin{abstract}
Background: Adolescence is a time of rapid physical growth and second only to the first year after birth during whichchildren gainupto 50\% of adult weight and more than $20 \%$ of adult height. Somatic growth can be altered by providing optimal nutrition, modifying eating patternsand behaviour. Further it can be a second opportunity to catch up growth with requirements of nutrients being high. The overall nutrition status is very poor among adolescent girls of poor rural groups. So short stature is common. Maternal stunting is a factor of increased risk and it can be attributed to chronic malnutrition. Nutritional intervention during this period can help the adolescent girl to achieve the targeted height to some extent.

Objective: To study the impact of nutrition on the height of adolescent girls aged 10-18 years who are short statured due to nutritional deprivation.

Method: A total of 128 adolescent girls between ages 10-18 years who were below 2SD height for age and nutritionally deprived were selected and divided into two groups' controls and cases with 64 in each group. Nutritional intervention in the form of balanced diet with iron supplementation and deworming was given to control group and case group was provided with above diet, iron and in addition micronutrients like zinc,calcium, vitamin D, vitamin A and B-complex vitamins and milk. Both groups were followed for one year with monthly checkups and data analyzed.

Results: Nutritional intervention in this study showed a significant increase in height of both groups. Themean height attained in the control group was $6.83 \mathrm{cms} /$ year and $7.97 \mathrm{cms} /$ year in the test group. When compared with the control group, test group had an additional increase in height of $1.14 \mathrm{cms}$ which is statistically significant $(p<0.001)$.

Conclusion: Adequate nutrition and micronutrient supplementation of the diet of adolescent girls who are short statured and nutrionally deprived can cause a significant catch up growth in height and improve their general condition.
\end{abstract}

Keywords:Adolescent girls, malnutrition, short stature, nutritional intervention,micronutrients

\section{Introduction}

The foundation of adequate growth and development is laid before birth,during childhood and is followed during adolescence. Growth during adolescenceis faster than at any other time in an individual's life except the first year. Adolescent girls are the future generation of any country and their nutritionalneeds are critical for the well being of society ${ }^{1}$.The high rate ofmalnutrition in girls not only contributes to increased morbidity and mortalityassociated with pregnancy and delivery,but also to increased risk of deliveringlow birthweight babies. This leads to the intergenerational cycle of malnutrition ${ }^{2}$. Adolescence is a time of rapid physical growth, second only to the first year after birth, during which, children gain up to 50\% of their adult weight and skeletal mass and more than $20 \%$ of their adult height which marks the end of growth in height and the attainment of adult height. ${ }^{3}$ The girl begins her adolescent growth spurt at an average of about 10 years and grows at peak velocity at about 12 years. The hormones mediating the pubertal growth spurt such as sex steroids and growth hormone are modulated to a great extent by nutritional factors ${ }^{1}$. All these changes necessitate some special nutrition needs.Optimalnutrition during this period of life is therefore crucial. Poor nutrition during adolescence will affect adult body sizeresulting inshortness and once final height is attained, stunting becomes a permanentconsequence. ${ }^{4}$

The overall nutritionstatus is verypoor among adolescent girls of rural population in India. The risk is more when the stature is below $145 \mathrm{~cm}$, which is the case of 16-18\% of women in Asia, 11-15\% of women in Latin America and 3\% in Africa.The growth spurt of adolescent girl is a good chance for catching up growth deficit of childhood. ${ }^{5}$ So, if there is chance of catch-up growthin height, adolescent girl can be provided with 
afinal chance for intervention to promote additional growth, with potential benefit in terms of heightand of diminished obstetric risk. ${ }^{6}$

\section{Aim of the study}

This study is designed to know the impact of nutritional intervention on height increase in adolescent girls between age groups 10-18 years, by comparing two groups, cases and controls.

\section{Material and methods}

This study was a prospective interventional study conducted in adolescent girls 10-18 years old who attended outpatient center inNiloufer hospital and stretched over a period of 1.5 years from January 2015 to July 2016.All the girls attending outpatient clinic for short stature were screened by collecting the demographic data,nutritional history and the relevant clinical history.Girls not attained menarche, affected with systemic diseases,genetic disorders and whose parents are short statured are excluded from the study. Girls with short stature and attained menarche and not affected with any other medical conditions were included.

Thestudy procedure was explained and consent was taken from parents and subjects. All precautions were taken for the proper measurement of height and data plotted in a growth chart. A Cut of value of height for age below 2SD according to standard growth chart of NCHS was considered as short stature.A total of 128 adolescent girls 10-18 years were included in the study and girls were divided into 2 groups cases and controls with 64 in each group.Nutrition and Dietaryadvice wasgiven with carbohydrate intake of $50-60 \%$ of total calories i.e. $15-30 \mathrm{mg} / \mathrm{kg} / \mathrm{day}$,protein intake of $10-15 \%$ of total caloriesi.e $1.5-2 \mathrm{~g} / \mathrm{kg} / \mathrm{day}$, fat intake of $10-15 \%$ of total calories and Iron supplementation of $10-15 \mathrm{mg} / \mathrm{kg} /$ day till hemoglobin is normalized and Deworming done in both cases and control groups.In addition Micronutrients supplementation was done in cases (64) which includes Zinc- 9-10mg/day elemental, glass of milk every day i.e $200 \mathrm{ml}$, Calcium supplement of $1000 \mathrm{mg} / \mathrm{day}$ along with 400 IU of Vitamin D daily, Vitamin A 2 lakh IU every 4 monthly and nutritional advice regarding an egg a day and leafy vegetables and B-complex vitamins was given. Both groups were followed up for one year with monthly checkups and data was analyzed.RecommendedEnergyAllowancesforAdolescents Girls ranged from 1970 -2060 kcal per day(ICMR 1989).

\section{Observation And Results}

The 128 female adolescents in the study were divided into 2 groups' controls(64) and cases(64)each and the data was analyzed for descriptive statistics which includes mean age, standard deviation and mean height to know the nature of the sample.

Fig:1Graphical representation of two groups

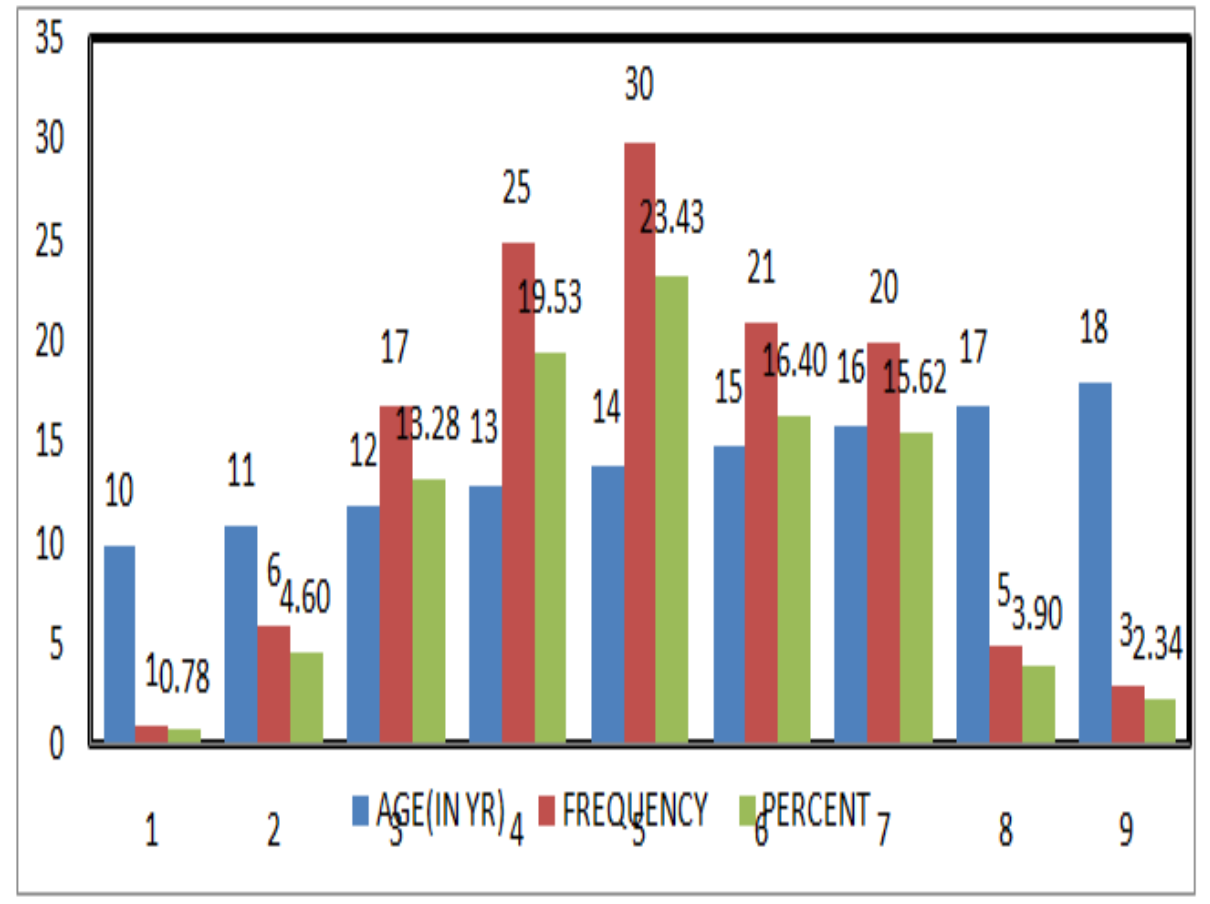


The maximum no of adolescents in this study are between ages 13-15 years accounting to nearly $58 \%$. In the age group 10 \&age group of 18 , only few were present in this study, accounting to only $3 \%$.

Table 1: Descriptive Statistics Of The Sample Selected

\begin{tabular}{|l|l|l|l|l|l|}
\hline Group & No Of Females & Mean Yrs & S.D Years & \multicolumn{2}{|c|}{ Range Of Age } \\
\hline & & & & Min & Max \\
\hline Control & 64 & 14.18 & 1.73 & 10 & 18 \\
\hline Cases & 64 & 14.12 & 1.60 & 10 & 18 \\
\hline Total & 128 & 14.15 & 1.66 & 10 & 18 \\
\hline
\end{tabular}

Fig 2: The mean age of control is 14.18 and of cases are 14.12

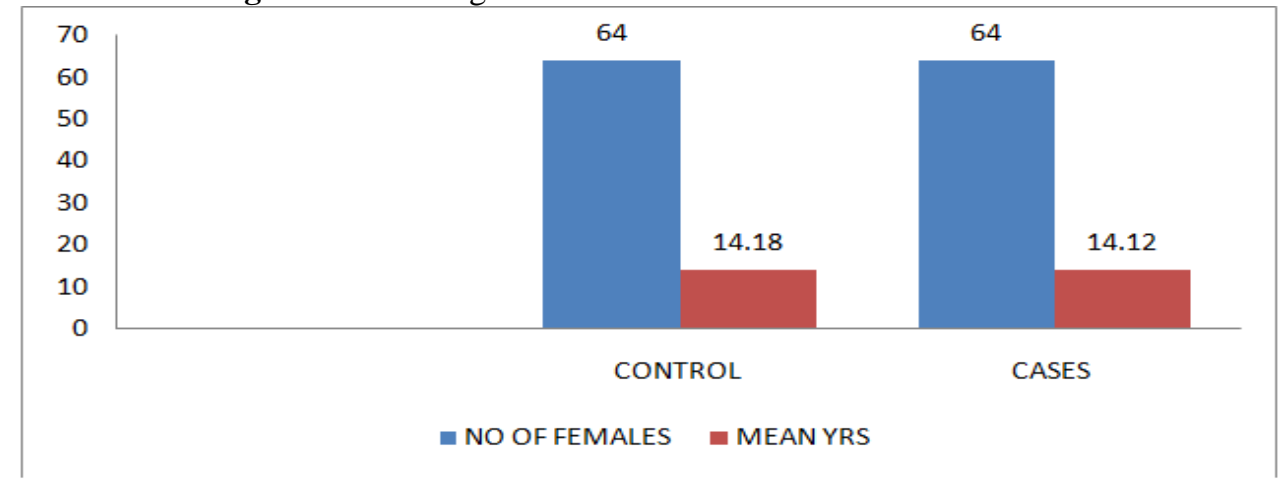

Table2: Descriptive Statistics Of Control Group

\begin{tabular}{|l|l|l|l|l|l|l|}
\hline Group & $\mathrm{N}$ & $\begin{array}{l}\text { Mean Height before } \\
\text { intervention }(\mathrm{cms})\end{array}$ & $\begin{array}{l}\text { Mean Height after } \\
\text { intervention }(\mathrm{cms})\end{array}$ & $\begin{array}{l}\text { Height gain } \\
(\mathrm{cms})\end{array}$ & S.D. \\
\hline control & 64 & 133.07 & 139.9 & 6.83 & 4.82 \\
\hline
\end{tabular}

Fig: 3 Mean Height Gain In Control Group

\begin{tabular}{|c|c|c|}
\hline 142 & & 139.9 CMS \\
140 & & \\
138 & 133.07 & \\
136 & CMS & \\
134 & & \\
132 & & \\
130 & & MEAN HT AFTER \\
128 & MEAN HT BEFORE & INTERVENTION \\
& INTERVENTION & \\
& &
\end{tabular}

Table: 3 Descriptive Statistics Of Cases

\begin{tabular}{|l|l|l|l|l|l|}
\hline Group & $\mathrm{N}$ & $\begin{array}{l}\text { Mean height before } \\
\text { intervention }(\mathrm{cms})\end{array}$ & $\begin{array}{l}\text { Mean height after } \\
\text { intervention }(\mathrm{cms})\end{array}$ & $\begin{array}{l}\text { Height } \\
\text { Gain }(\mathrm{cms})\end{array}$ & S.D \\
\hline Cases & 64 & 128.98 & 136.95 & 7.97 & 5.63 \\
\hline
\end{tabular}

Fig: 4 Mean Height Gain In Case Group

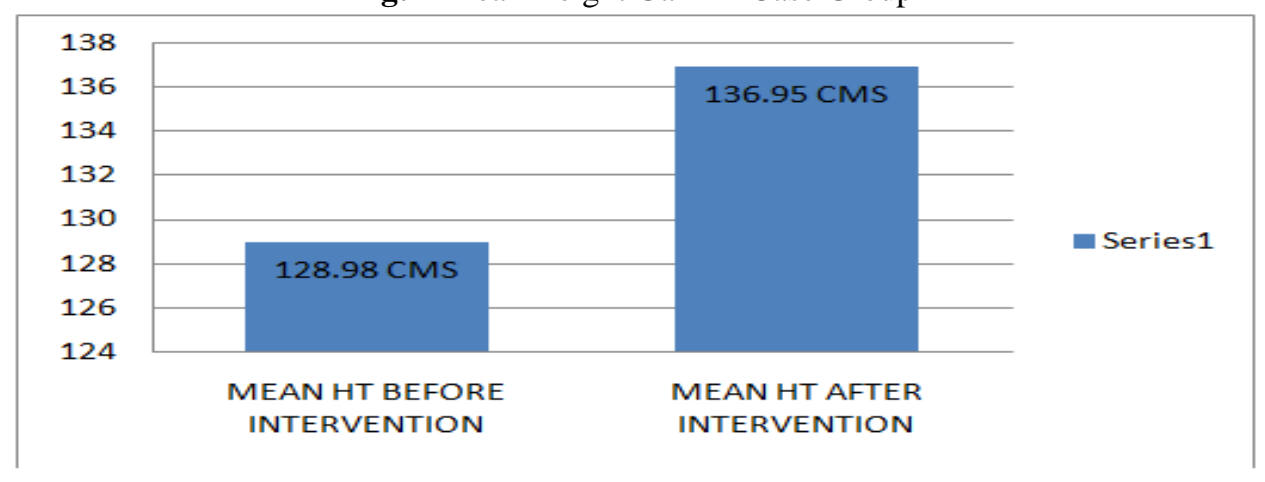


Table: 4ComparisionOf Height Gain In Controls And Cases

\begin{tabular}{|l|l|l|}
\hline GROUP & N & MEAN HT GAIN (CMS) \\
\hline CONTROL & 64 & 6.83 \\
\hline CASES & 64 & 7.97 \\
\hline
\end{tabular}

Fig: 5 Graph showing comparision of height gain in controls and cases

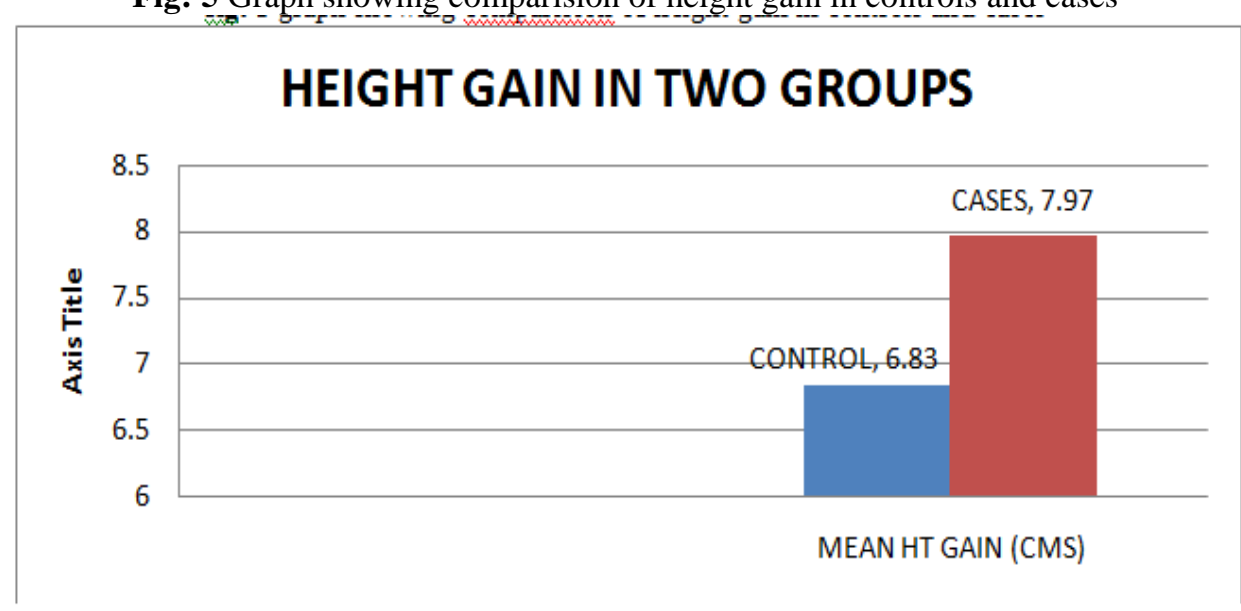

Statistical Significance Of The Study:Repeated Measures Anova was carried out to see whether the group time interaction was statistically significant. Main effects group time shows significant effect on the height.This suggests that the controls are taller in the base line and over a time period of 1 year, there was a significant increase in height $(\mathrm{P}<0.01)$. However the interaction between group time suggests that cases $(7.97 \mathrm{cms})$ had a statistically significant $(\mathrm{P}<0.001)$ height gain over controls $(6.83 \mathrm{cms})$ over a period of 1 year.

\section{Discussion}

The global burden of under nutrition remains high with little evidence of change in many countries. ${ }^{7,8}$ The evidence of the potential nutritional interventions was reviewed and estimated their effect on nutrition-related outcomes of female adolescents. ${ }^{9,10,11}$ Among girls, the "growth spurt" normally takes place between 12 and 18 months before the ageof menarche,which occurs between the ages of 10 and 14 . Then growth in stature continues for up to 7years.In undernourished populations, growth rate during adolescence is slower. ${ }^{12}$ Using maximum growth spurt or menarche as an indicator, maturation may be delayed in malnourishedgirls by an average of two years. Maternal stunting is a factor of increased obstetric risk, and it can be attributed to chronic malnutrition. The intervention in our study showed a significant increase in height of both groups. The growth velocity in mid puberty is $9-10 \mathrm{cms}$ on average and it decreases sharply to $6 \mathrm{cms} / \mathrm{yr}$ after puberty and decreases $1-1.5 \mathrm{cms} / \mathrm{yr}$ till $16-17 \mathrm{yrs}$ in girls. The intervention showed a significant increase in height of both groups. The average height gain after menarche is $6 \mathrm{~cm} / \mathrm{yr}$. Control group attained mean height $6.83 \mathrm{~cm} / \mathrm{yr}$. Test group attained mean height $7.97 \mathrm{~cm} / \mathrm{yr}$.

When compared with control group, test group had an additional increase in height of $1.14 \mathrm{cms}$ which is statistically significant $(\mathrm{p}<0.001)$. The results of this study are satistically significant and on par with the other few studies carried out.Compared with Golden $\mathrm{MH},{ }^{13}$ which showed definite catch up growth with $\mathrm{P}<0.01$, this study has a significant $\mathrm{P}<0.001$ value with increase in height of $7.97 \mathrm{cms}$.Proos, Hofvander\&Tuvemo ${ }^{14}$ showed a full catch up growth after nutritional intervention with significant p-valueof 0.01 and when compared to this study this had a good increase in height which is statistically significant.Coly AN,Milet $\mathrm{J}^{15}$, studied a huge population of 2874 which showed a $9 \mathrm{cms}$ catch up growth and is statistically significant $\mathrm{p}<0.001$. This when compared with the present study in which the sample size is very small, though a significant $\mathrm{P}$ value is noted, full catch up growth was not achieved. Simond $\mathrm{KB}$ and Simond $\mathrm{F}^{16}$ had only aconsiderable catch up growth, but when compared to the present study had good catch up growth of $\mathrm{P}<0.001$ and was statistically significant.

Micronutrients play a vital role in growth. ${ }^{7}$ Studies in India have shown deficiencies in the intake of all nutrients, particularly iron, calcium, vitamin A and vitamin $C^{8}$.Iron deficiency is the most widespread form of micronutrient malnutrition around the world and yet it is the most neglected. ${ }^{17}$ It is regarded as the main nutritional problem in adolescents, particularly so in girls. ${ }^{18,19}$ Considering all the causes of anaemia and their relative importance throughout the life cycle and using a case study, it was concluded that the low bioavailability of dietary iron was the principal determinant at all ages, and that intestinal helminths were also a major factor, particularly among school-age children and adolescents. Where the prevalence of anaemia is high (above 30\%), it is recommended that iron supplementation (plus folate in girls and women) be universally 
implemented in pregnant women, under-five children, and girls and women from 10-49 years of age (UNICEF/WHO 1994). ${ }^{20}$

Iron deficiency also affects linear growth and so supplementation has a positive effect on linear growth. It is now apparent that vitamin A deficiency is widespread among adolescent girls and women, and that it contributes to maternal mortality as evidenced in supplementation studies (West et al, ${ }^{21}$. High-dose vitamin A supplementation improves the linear growth of children with very low serum retinol.Regarding zinc, the deficiency is suspected to be widespread in many developing countries. It is associated with poor growth and development, and impaired immunity. Observational studies have suggested an association between maternal zinc deficiency and pregnancy outcome.Studies have shown a positive impact on height of adolescents (Kenneth H brown, Janet Pearson 2003). ${ }^{22}$

Zinc deficiency has been associated with anabolic hormonal deficiency like growth hormone and insulin. It enhances bone formation and inhibits bone loss. Limited intake of zinc-containing foods may affect physical growth as well as development of secondary sex characteristics.

Calcium is a primary bone-forming mineral that has to be supplied by the diet. Calcium accretion is substantially higher during the period of rapidgrowth in adolescence. This peaks at around $320 \mathrm{mg} / \mathrm{d}$ for girls, but can be greater than $500 \mathrm{mg} / \mathrm{d}$ in some individuals. Significant accretion continues in young adults after the cessation of linear growth during the period of skeletal consolidation. Hence, it is plausible that calcium intake during adolescence and young adulthood affects skeletal growth and bonemineralization and influences peak bone mineral mass and increase inheight.(weaver et al 1999). ${ }^{23}$

Several epidemiological studies have suggested an association between the intake of calcium-rich foods, such as milk, during teenage years and young adulthood with higher bone mineral mass in old age.One problem with nutritional deficiencies, as suggested by results of supplementation studies on linear child growth is that once a specific deficiency is controlled, another one may becomelimiting, and the process could well be endless.The strongest evidence that cow's milk stimulates linear growth comes from observational and intervention studies in developing countries that show considerable effects. Adding cow's milk to the diet of stunted children is likely to improve linear growth and thereby reduce morbidity. Milk has potential bioactive compounds like bioactive peptides,IGF-1,calcium and other minerals likely to help in linear growth.In developing countries, adolescent or adult, are more likely to be undernourished, and food supplementation is seen as a potentially effective intervention. ${ }^{24}$ Meta-analyses of data from controlled trials revealed improvements, however modest, of fetal growth and birth weights with balanced energy/protein supplements.

The biggest challenge of adolescent nutrition is to decrease theprevalence of malnutrition among adolescents by improving their nutritional status. Multisectoral collaboration for adolescent health and nutritionshould be led by the health sector. Public health interventions in particular has the potential to affect adolescents and children, especially when disseminated throughchannelsthat reach a majority of adolescents.Social marketing approach, behaviour change through communication,mobilizing the family and communities, school based nutrition interventions such as regular nutritional screening,providing micronutrient supplements, ensuring consumption and nutritionbehaviour development are the most cost-effective. ${ }^{25,26}$

\section{Conclusion}

A large number of adolescents suffer from chronic malnutrition and anaemia, which adversely impacts their health and development. The high rate of malnutrition in girls not only contributes to increased morbidity and mortality associated with pregnancy and delivery, but also to increased risk of delivering low birth-weight babies. Addressing the nutrition needs of adolescents could be an important step towards breaking the vicious cycle of intergenerational malnutrition.Dietary intake with respect to adequate availability of food in terms of quantity and quality(particularly, the mean caloric intake) anddiscriminations against girls can greatly affect health. This study has proved that adequate nutrition and micronutrients, if provided to adolescent girls who are nutritionally deprived and short statured can cause a significant catch up growth in height and decrease the serious side effects of maternal, neonatal and infant complications that occur due to short statureand improve their general condition.

\section{References}

[1]. ACC/SCN (2000) Ending Malnutrition by 2020: an Agenda for Change in the Millennium. Final Report to the ACC/SCN by the Commission on the Nutrition Challenges of the 21 st Century, Administrative Committee on Coordination/Subcommittee on Nutrition, www.unscn.org/layout/modules/resources/files/2020Report_1.pdf (accessed 11February 2015)

[2]. Aguayo, VM, Paintal, K and Singh, G (2013) 'The Adolescent Girls' Anaemia Control Programme: a decade of programming experience to break the inter-generational cycle of malnutrition in India', Public Health Nutrition16, 9, pp 1667-76. doi: $10.1017 /$ S1368980012005587.

[3]. Brasel J. Changes in body compositionduring adolescence. In: Myron Wied, ed.Adolescent nutrition. New York; JohnWiley\& Sons, 1982.

[4]. Spear BA. Adolescent growth anddevelopment. J Am Diet Assoc. 2002Mar; 102(3 Suppl): S23-9.

[5]. Gopalan c Growth of affluent Indian girls during adolescence NFI,Science.Rep.. 1989,10:1-74 
[6]. Horton, S, Webb, P, Lartey, A, Black, RE, Lancet Nutrition Interventions Review Group, and Maternal and Child Nutrition Study Group (2013) 'Evidence-based interventions for improvement of maternal and child nutrition: what can be done and at what cost?' The Lancet 382, 9890, pp 452-77.doi: 10.1016/S0140-6736(13)60996-4.

[7]. Black, RE, Allen, LH, Bhutta, ZA, Caulfield, LE, de Onis, M, Ezzati, M, Mathers, C, Rivera, J, and Maternal and Child Undernutrition Study Group (2008) 'Maternal and child undernutrition: global and regional exposures and health consequences'

[8]. Vijayaraghavan K, Venkaiah K, Damayanthi K, Nayak MU. NNMB Report on diet \& nutritional status of adolescents, National Institute of Nutrition, India, 2000

[9]. Adelman, S, Alderman, H, Gilligan, D and Konde-Lule, J (in press) Addressing Anemia through School Feeding Programs: Experimental Evidence from Northern Uganda (Draft). Washington: International Food Policy Research Institute (IFPRI).

[10]. Adelman, SW, Gilligan, DO and Lehrer, K (2008) 'How Effective are Food for Education Programmes? A critical assessment of evidence from developing countries'. In Food Policy Review Washington: International Food Policy Research Institute.

[11]. Spear BA. Adolescent growth anddevelopment. J Am Diet Assoc. 2002Mar; 102(3 Suppl): S23-9.

[12]. Alam, N, Roy, SK, Ahmed, T and Ahmed, AM (2010) 'Nutritional status, dietary intake, and relevant knowledge of adolescent girls in rural Bangladesh', Journal of Health, Population and Nutrition28, 1, pp 86-94.

[13]. Golden MH. Is complete catch-uppossible for stunted malnourishedchildren? Eur J ClinNutr. 1994 Feb; 48Suppl 1:S58-70.

[14]. Menarcheal age and growth pattern of Indian girls adopted in Sweden. II. Catch-up growth and final height.Proos LA ${ }^{1}$, Hofvander Y, TuvemoT.Indian J Pediatr. 1991 Jan-Feb;58(1):105-14

[15]. Preschool stunting, adolescent migration, catch-up growth, and adult height in young senegalese men and women of rural origin.Coly $\mathrm{AN}^{1}$, Milet J, Diallo A, Ndiaye T, Bénéfice E, Simondon F, Wade S, Simondon KB.J Nutr. 2006 Sep;136(9):2412-20

[16]. Preschool stunting, age at menarche and adolescent height: a longitudinal study in rural Senegal KI3 Simondon'i2, F Simondon'y2, I Simon'.2, A Diallo2, E P Traissac' and B Maire'European Journal of Clinical Nutrition (1998) 52 p,412-418

[17]. Beard JL. Iron requirements inadolescent females. J Nutr. 2000 Feb;130 (2S Suppl):440S-442S.

[18]. Beard JL. Iron requirements inadolescent females. J Nutr. 2000 Feb;130 (2S Suppl):440S-442S

[19]. Ahmed F, Zareen M, Khan MR, Banu CP, Huq M and Jackson A.Dietary pattern, nutrient intake and growth of adolescent school girls in urban Bangladesh. Public health Nutrition. 1998,(2):83-92.

[20]. WHO UNICEF 1994 Guidelines for the Use of Iron Supplements to Prevent and Treat Iron Deficiency Anemia Rebecca J. Stoltzfus Michele L. Dreyfuss International Nutritional Anemia Consultative Group (INACG)

[21]. Double blind, cluster randomised trial of low dose supplementation with vitamin A or $\beta$ carotene on mortality related to pregnancy in NepalKP West Jr, J Katz, SK Khatry, SC LeClerq, EK Pradhan... - Bmj, 1999 - bmj.com

[22]. Hotz C, Peerson JM, Brown KH. Suggested lower cutoffs of serum zinc concentrations for assessing zinc status: reanalysis of the second National Health and Nutritional Examination Survey Data (1976-1980). Am J Clin Nutr.2003;78:756-64.

[23]. Weaver CM, Peacock M, Johnston CCJr. Adolescent nutrition in the preventionof postmenopausal osteoporosis. J ClinEndocrinolMetab. 1999 Jun; 84(6):1839-43.(192) Whitaker RC, Wright.

[24]. World Health Organization / Food and Agriculture Organization. Preparation use of food based dietary guidelines. WHO technical report series; 880. Geneva: WHO 1998 (http://whqlibdoc. 77 Adolescent Nutrition: A Review of the Situation in Selected SouthEast Asian Countries who.int/trs/WHO_TRS_880.pdf , accessed 30 May 2005).

[25]. Zeitlin MF, Formacion CS. Nutrition education. Chapter 5. In: Nutrition Interventions in developing countries. Cambridge: Oelgeschlager, Gunn \& Hain, 1981.

[26]. Nutrition of the school-aged child. SCN News. 1998 Jul; 16: 1-65.

\footnotetext{
* Dr. Punukollu srinivas. "A Study of Impact of Nutrition on Targeted Height among Adolescent Girls ." IOSR Journal of Dental and Medical Sciences (IOSR-JDMS) 16.7 (2017): 27-32.
} 